\section{ABSTRACT OF LECTURES}

\section{ANATOMY, PHYSIOLOGY, AND ZOOLOGY OF THE CETACEA.}

Delivered at the Royal College of Surgeons of England.

\section{By W. H. FLOWER, F.R.S., LL.D.,} Hunterian Professor of Comparative Anatomy.

Lecture IV.-The Axatomy of the Lesser Rorqual. (CONTINUED.)

THE pelvis consists of two bars of bone placed parallel to one another on each side of, and below, the vertebral column, to which it is quite unconnected except by the soft parts. Those bones are situated in the long axis of the body. In the young animal, they are cartilaginous, but become ossified later in life. The upper surface of each is prolonged upwards into a small process which has been thought by some observers to correspond to the ilium of other mammals, while the anterior end of the har corresponds to the pubis, and the posterior to the ischium. These homologies are, however, uncertain, especially as the whole bone is ossified from a single centre. The under margin is rough, for the attachment of the crus penis. The bony nodules, united by fibrous tissue to the centre of the external surface of the pelvic bones, which represents the femora, and which were first observed by Professor Flower when dissecting a greater rorqual, Balcnopter a musculus, a few years ago, appear to be absent from the lesser rorqual, since, up till this time, they have not been observed; probably, if they do exist, they are cartilaginous, and, from being of very small size, are lost during maceration. In the Greenland whale, they are much larger and better developed. There is no trace of the presence of a tibia or fibula.

The mouth is remarkable for its great size and width, compared to the size of the body. The tongue, which looks like a large soft pillow or cushion, is flat, and attached to the floor of the mouth all round the tip close to its margin, so that it cannot be protruded beyond the lips. The whole surface is covered with small papillæ, and much grooved. The mucous membrane between the tongue and mandible is thrown into longitudinal folds, which correspond to the folds of the skin under the chin. The teeth are absent in the adult, but, in a foetus nine inches long Eschricht found a complete set, consisting of forty-four in the upper, and forty in the lower jaw. Those teeth attain their greatest size when the animal is three feet long, but by the time of birth, they have entirely disappeared. The observations of Eschricht have been confirmed by Julin, who has figured and described the dentition of the lower jaw very fully. In his specimen, there were forty-one teeth, which he found to be developed in the same manner as in terrestrial mammals; those situated anteriorly were conical and simple in form, while the posterior teeth were cuspidate, and resembled somewhat the normal mammalian molar teeth. After the transitional teeth have been lost, the dentary grooves of the upper jaw become covered by the mucous membrane of the palate, which is greatly thickened, very vascular, and thrown into numerous folds. These latter become greatly elongated, and are arranged transversely to the axis of the mouth. At their free extremity, they are frayed out into a fringe-like border. Each of the fringe-like projections contains blood-vessels and nerves, for the nourishment and innervation of the whalebone. From the sulci on each side of these folds, a horny substance grows, and extends downwards along the folds into the mouth; this is the baleen, or whalebone, as it is usually called. It consists of a series of blades united to the palate, and united to one another for a short distance, by an intermediate epithelial tissue, which is situated between them. They are much elongated externally, so that, individually, each resembles a triangle, the external edge of which is vertical, that directed inwards towards the centre of the mouth is oblique, while the third is attached to the palate. Each plate is composed of bristle-like hairs united by a connecting substance almost to their extremities, where they are free, and give an appearance, when the plates are in position, as if the sloping surface were covered with pigs' bristles, as Aristotle described it. The hairs are seen, on transverse section, to be formed of a cortical and a medullary portion. Their function is to act as a fine sieve, so as to prevent the smaller animals upon which the whale lives from passing between the plates. It has been suggested by Professor Turner that they act also as tactile sensory organs, since he believes that he has been able to trace nerves passing to them. The whalebone is entirely confined to the upper jaw, along the whole outer border of which it extends. In the Balanoptera rostrata, it is continuous all round the jaw, though in some whales it is not continuous in front. Its length diminishes both anteriorly and posteriorly, the longest blades being situated about the centre of the jaw. The homology of whalebone may best be seen by comparing it to the palate of some of the ruminants, such as the giraffe or the roebuck, in which the palate is covered with ridges. Clearly it is not homologous to the teeth, though it is their analogue, as it is a subsequent development from a different part of the mucous membrane of the mouth. The posterior part of the mouth is suddenly terminated by the palate and fauces, so that the mouth-cavity is completely shut oft from the larynx and pharynx. The œsophagus is very small in this, and indeed in all the whalebone whales. The stomach is very complex, consisting of five compartments. The first, to which the lower end of the oesophagus is attached, is egg-shaped, and is the reservoir into which, in the adult animal, the food passes, in the first instance, to be partially digested; it is lined by a thick corrugated layer of epithelium. The second compartment is curved and tubular; at the opening into it from the first stomach, the thick corrugated epithelium ceases. Its mucous membrane is thick, corrugated, and very glandular. The third compartment is divided into three divisions, of which the first is the smallest. The pylorus, which is well marked, is situated at the end of the third division, or fifth stomach, as it is called. The intestinal canal is simple, about five times the length of the animal, and possesses a crecum. In its interior, there are folds of the mucous membrane corresponding to the valvulæ conniventes in man. The testes remain in the abdominal cavity, and never descend into a scrotum. Externally, there is no sign of a penis, that organ being retracted within the abdominal cavity also; the only trace of genital organs to be seen externally in the male, being a preputial aperture. The penis is long and thin. Vesiculæ seminales and Cowper's glands are absent. The uterus is bicornate. The nipples are concealed from view between two slits on each side of the vulva. The mammary gland is very large, and contains large ducts, which act as reservoirs for the milk, from which that fluid can be rapidly injected into the mouth of the young. The spleen is attached to the first stomach. The kidneys are excessively lobulated, each resembling in appearance a bunch of grapes.

\section{MALIGNANT PAPILLARY DERMATITIS OF THE} NIPPLE* AND THE BREAST-TUMOURS WITH WHICH IT IS FOUND ASSOCIATED.

ILLUSTRATED BY SPECIMENS EXHIBITED IN THE PATHOLOGICAI MUSEUM OF THE BRITISH MEDICAL ASSOCIATION AT CAMBRIDGE.

\section{By GEORGE THIN, M.D.}

A CONSIDERABLE number of cases have been published, during the last few years, in which an obstinate affection of the skin of the areola and nipple had preceded the development of cancerous tumours of the breast-the coincidence having been first observed and described by Sir James Paget. The nature of the affection of the skin, and the pathological significance of the structure of the breast tumours, having given rise to questions regarding which unanimity has not been attained, I believed it would be useful to show, at the meeting of the British Medical Association at Cambridge, the preparations which had suggested the opinions explained in a paper on the subject, read before the Royal Medical and Chirurgical Society during the preceding session of the Society.

The preparations exhibited were obtained from four cases. In all the four cases, the changes in the skin showed the same pathological condition; but the tumours were in no two instances exactly alike. They agreed in being examples of a variety of breast tumours which, I think, will be most conveniently known as duct-cancer. None of them were scirrhous tumours (in the true pathological sense, as equivalent to parenchymatous cancer-the cancer which develops from the secreting epithelium of the acini). In certain points, they agreed in structure and these were points which they had in common with tumours which are often described in England as adenomata, or adenoid tumours.

Opinions regarding the exact nature of this class of cases, and the connection which they have with the duct epithelium, will probably vary

* This name has been adopted since the paper was placed in the hands of the editor of the Journal. It appeared desirable to select a designation that should, to some extent, have reference to the pathological changes which characterise the disease, and more especially to discontinue in this connection the use of the term "eczema of the nipple", as tending to produce confusion, by giving one nam distinct morbid conditions. 
considerably until full details regarding a considerable number of them have been published. Concerning the nature of the breast tumours, more particularly, opinions will differ on account of the opposite stand-points from which pathologists look at morbid growths of the mammary gland, and also on account of the somewhat confusing effect of the want of a settled nomenclature.

An attempt will be made in this paper to convey an idea of the nature of the growths in these four cases, by showing, pictorially, a few of the more characteristic parts of the sections.

CASE I. * - This case was that of a woman, aged 33 , the mother of children, a patient, under the care of Mr. Henry Morris, at the Middlesex Hospital. The breast was removed in March I879, and contained several nodules of recent and rapid growth, which were diagnosed as cancerous. The superficial disease had begun on one point of the nipple, from which it slowly spread, and had existed from four to five years before any tumour was felt in the breast. I had an opportunity of preparing for examination the breast, the skin, and several cancerous glands from the axilla, immediately after their removal. A vertical section through the skin showed the following changes.

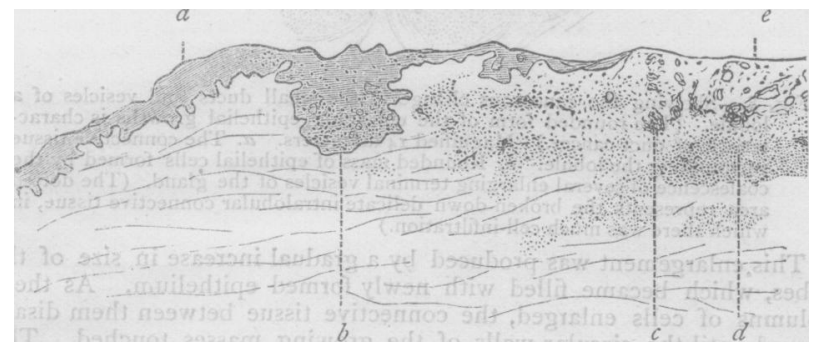

Fig. r.--Section through the skin; magnified fourteen diameters. $a$. The healthy epidermis. 6. Thickened portion of the epidermis separating the healthy from the diseased part of the skin. $c$. Isolated islands of epidermis surrounded by connective tissue and exudation cells. $d$. Stratum of exudation dermis in the diseased area.

The epidermis was much broken up and disintegrated. A thin remnant of the horny layer, uneven and ragged, lay on the surface of the diseased skin. Below this thin strip of dead epidermis, the contour of a thickened rete mucosum could mostly be distinguished, although, at some parts, it was impossible accurately to define the deep border where it was in contact with the subjacent mass of cell-infiltration; but, even where the rete mucosum maintained its outlines, so many of the constituent cells had perished that the structure existed only in skeleton form. Many cells had disappeared entirely. Of those which remained, a great number showed the usual stages of cell-degeneration-namely, a swollen nucleus, disappearance of the nucleus, and swollen or vacuolated cell-substance, enclosing an altered nucleus or the cavity from which it had disappeared. (Fig. 2.)

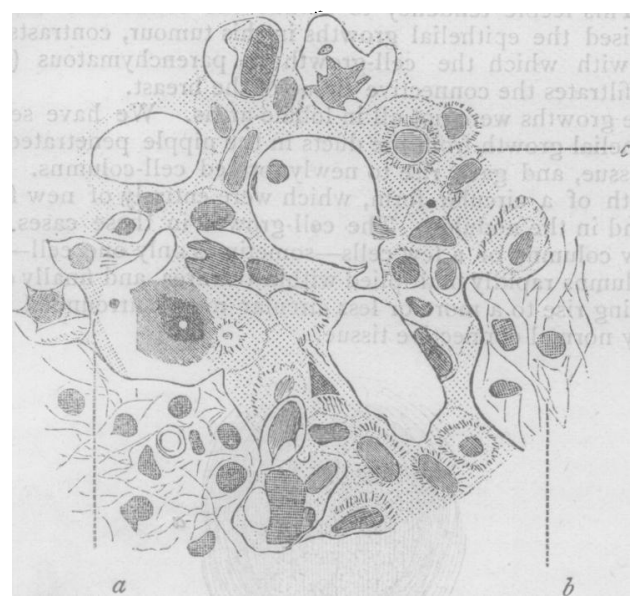

Fig 2.- Showing the changes in the epidermic cells in the diseased area ; mag nified 500 diameters. $a$. The deep border of the epidermis, $b$. Connective tissue. c. "Prickle cells" of the rete mucosum.

For a full account of the case clinically, see a paper by Mr. Morris in the Medico-Chimurgical Transactions, vol. 63, p. 44 .
This condition pervaded the entire thickness of the rete. At other parts the destruction of the epidermis was even more advanced, the thin ragged horny layer covering a kind of granulation tissue, in which isolated islands of diseased epidermis were present. (Fig. 3.)

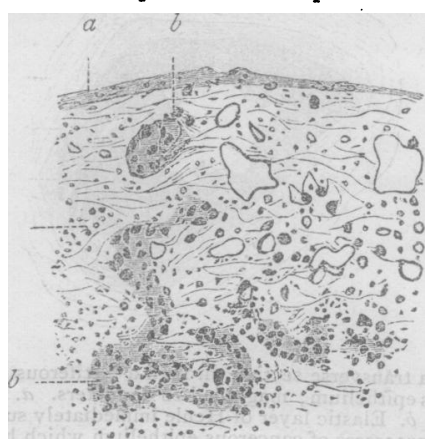

Fig. 3.-Showing detached fragments of epidermis surrounded by connective tissue. $a$. Remnant of epidermis on the surface. $b, b$. Fragments of epidermis surrounded by connective tissue. c. Cell-infiltration in the papillary layer.

Beneath the diseased rete mucosum, the connective tissue of the papillary layer had undergone extensive changes. In the part nearest to the healthy skin, a considerable amount of cell-infiltration existed amongst the bundles; but, nearer to the nipple, this cell-infiltration became extreme, and occupied the position of the bundles of the white fibrous tissue. The normal bundles of the part had disappeared, and in their place (in so far as the mass of cell-infiltration permitted anything to be seen) an amorphous granular substance was found.

In striking contrast to the condition of the pars papillaris (superficial layer of the corium), the bundles of the pars reticularis (the strong deeper layer of the corium) were found unaltered, although, between the more superficial bundles of this part of the cutis, there was a certain amount of cell-infiltration.

These changes indicate a morbid process, in which the rete mucosum and the papillary layer of the skin have undergone almost complete destruction ; and although, in perhaps both these structures, and certainly in the rete, a certain amount of vitality still existed, yet no signs of a reparative action were detected in either of them. A remarkable feature is the undisturbed condition of the tissues of the skin beneath the papillary layer.

The description which has just been given is sufficient to show, that the peculiar condition with which we are dealing in this case is not eczema (the name by which in these cases it has been usually designated); and this is still more clearly shown by examining the part of the section (Fig. I, $b$ ) which separates the sound from the unsound tissues. The line of demarcation is indicated sharply by the projection downwards into the cutis of a rounded wall of epidermis, on the further or healthy side of which the cell-exudation ceases. The epidermic cells of this bounding wall are, many of them, diseased (swollen, vacuolated, disintegrated) ; but, beyond it, the epidermis presents a normal appearance. This condition of the epidermis contrasts with the changes described by Biesiadecki as characteristic of eczema. (It is superfluous to remark that, in eczema, there is no destruction of the white fibrous tisue.) Superficially, the nipple was affected similarly to the surrounding skin.

Transverse sections, through the deeper parts of the nipple-tissue, showed that some of the lactiferous ducts were diseased. The diseased ducts were distended by an accumulation of cells, which, by the action of hardening fluids, had become agglutinated into a mass, only the outlines of the nuclei being distinct.

In one section (Fig. 4), I found that four finger-like columns of this cell-mass had broken through the wall of the duct, and advanced into the elastic layer, by which, as Henle has shown, the large ducts are surrounded.

The cells in these advancing processes were similar to those which filled the dilated duct. The nuclei were small, fairly uniform in size; and the protoplasm of the cells so feeble in resisting the action of hardening fluids, that the outlines of the individual cells were rarely to be seen. The contours of these outgrowths from the ducts were well defined. (Fig. 5.)

In some sections, there were found in the elastic layer groups of cells similar to those which blocked up the distended duct. (Figures 6 and 7.) The appearance was the same as might be expected if we imagine that the finger-like processes already described had changed 
their direction of growth, and turned downwards towards the deeper parts of the breast.

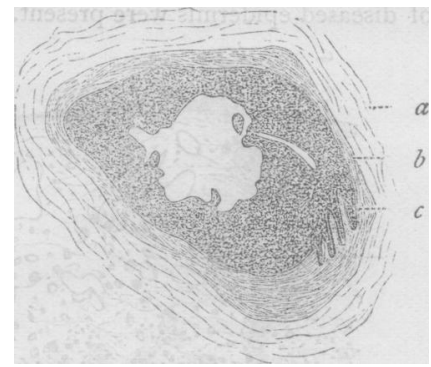

Fig. 4:- Showing a transverse section through a lactiferous duct, which is filled with cancerous epithelium; magnified 22 diameters. $a$. White fibrous tissue of the nipple. b. Elastic layer of Henle immediately surrounding the duct. $c$. Finger-like processes of cancerous epithelium which have broken through the membrana propria of the duct and are growing outwards through the elastic layer of Henle.

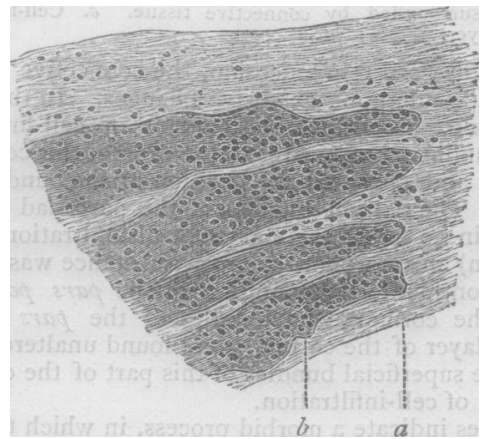

Fig. 5.-Showing the finger-like processes of frg. 4 more highly magnified; magnified 130 diameters. $a$. Elastic layer of Henle. $b$. Cancerous epithelium growing from a iactiferous duct of the nipple into the surrounding connecgrowing from

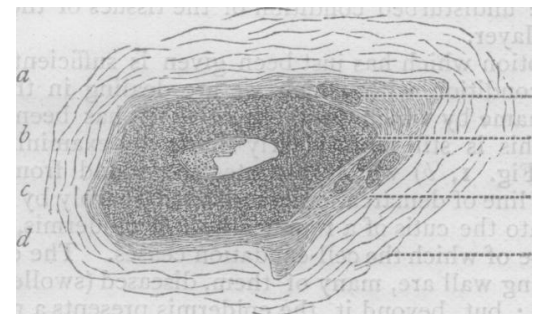

Fig. 6.-Showing a transwerse section of a lactiferous duct and columns of cancerous epithelium growing in a direction parallel to the long axis of the duct ; magnified 22 diameters. $a$. White fibrous tissue of the nipple. b. Elastic layer of Henle surrounding the lactiferous duct; $c$. Contour of the duct. $d$. Column of cancerous epithelium cut transversely.

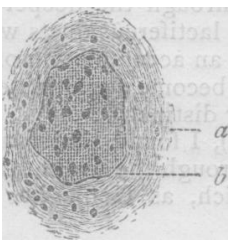

Fis. 7.-Showing a column of cancerous epithelium in the elastic layer of Henle more highly magnified. From the same preparation as Fig. 6; magnified r 30 diameters. a. Elastic layer of Henle. b. Column of Cancerous epithelium.

These appearances show that there is an abnormal growth of epithelium into the lumen of some of the ducts, and that there are points where this growth extends outwards beyond the duct-wall into the connective tissue of the nipple; the further development of these outgrowths taking place in a direction parallel to the duct and downwards into the gland. The epithelial character of the outgrowths is everywhere maintained.

An examination of the nodules in the breast showed that the epithelial growth was developing in two ways. Within the area of a lobule, it was found as an enlargement of its ducts and vesicles (Fig. 8).

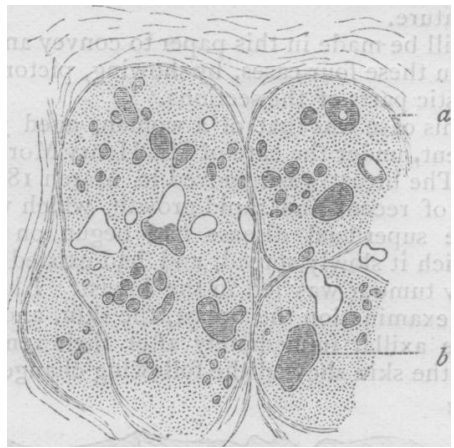

Fig. 8.- Showing the cancerous change in the small ducts and vesicles of a lobule. (The rounded form of the enlarging epithelial growths is characteristic of duct cancer.) Magnified i 4 diameters. $a$. The connective tissue surrounding the lobule. $b$. Rounded mass of epithelial cells formed by the coalescence of several enlarging terminal vesicles of the gland. (The dotted area represents the broken-down delicate intralobular_connective tissue, in
which there was much cell-infiltration.)

This enlargement was produced by a gradual increase in size of the tubes, which became filled with newly formed epithelium. As these columns of cells enlarged, the connective tissue between them disappeared until the circular walis of the growing masses touched. The membrana propria at the point of contact then gave way and disappeared, and the masses coalesced. The columns of cells thus formed retained the tendency to roundness; and, as the coalescing process extended, the area of a lobule was occupied by a few large circular masses. These columns of cells were sometimes hollow, and formed tubes. Sometimes they were filled with cells or cell-débris. In many instances, at least, the hollow space in the tube was formed by the disappearance of the débris. Sometimes a large cell-column was found filled with it. This débris, which is a product of cell-degeneration in its final stages, is a compact granular mass, showing no trace of cellstructures, and stains deeply with eosin. In appearance, it sometimes resembles blood-coagulum, for which, when found in tumours of this kind, I believe it is sometimes mistaken. The distinguishing features in these cell-columns were their roundness, their tubular formation, the frequency with which a membrana propria could be detected, and their comparatively little tendency to destroy the connective tissue. The soft connective tissue of the lobules speedily disappeared; but the firm interlobular tissue of the breast was more resistant, and the cellblocked areas were found encapsuled by a strong layer of frbrous tissue. This feeble tendency to invade the connective tissue, which characterised the exithelial growths in this tumour, contrasts with the rapidity with which the cell-growth in parenchymatous (scirrhous) cancer infiltrates the connective tissue of the breast.

But the growths were not all in lobule-areas. We have seen that new epithelial growth from the ducts in the nipple penetrated the connective tissue, and gave rise to newly formed cell-columns. Areas of cell-growth of a circular form, which were entirely of new formation, were found in the nodules. The cell-growth in these cases consisted of narrow columns of a few cells-sometimes only one cell-in depth. These columns rapidly multiplied within the area, and finally coalesced, again giving rise to a more or less circular mass, surrounded by a comparatively normal connective tissue.

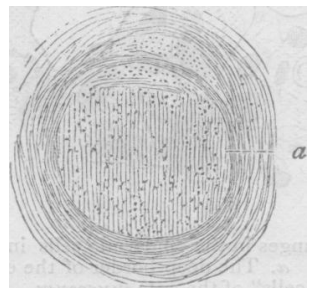

Fig. 9. - Showing the outlines of a circular area of connective tissue becoming filled with new epithelial formations; magnified 45 diameters $a$. The area of developing new formations of cancerous epittelium. 
The round cell-masses formed by the coalescence of the intralobular growths, or by the new extralobular formations, usually showed little tendency to invade the surrounding tissue. They were often represented in sections by rounded holes, entirely or partly empty of epithelium.

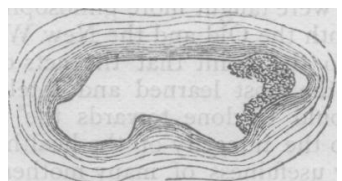

Fig. 10.-Showing a rounded hole from which the epithelial contents had disappeared, lying in connective tissue which was free from infiltration; magnified ${ }_{4}$ diameters.

These rounded cell-masses grew larger by the accretion of a new layer of cells on the periphery. This new cell-formation was foreshadowed by a change in the surrounding connective tissue; in stained preparations, a deeply tinged curve of fibrous tissue being sometimes found in a position corresponding to the new layer of cells observed in other sections.

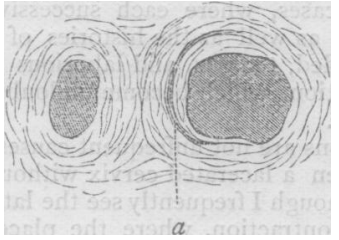

Fig. rr.-Showing two rounded cell-masses, in one of which (at a) a deeply stained curve of connective tissue foreshadowed the formation of new epithelial celis around the mass; magnified I4 diameters.

The cancerous formation in the axillary glands was found as rounded cell-columns having a distinct contour. The outlines of the individual cells could be seldom made out.

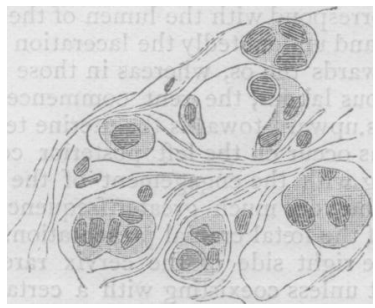

Fig. 12.-Showing the cancerous infiltration in an axillary gland; magnified 260 diameters.

[To be continued.]

The Killarney District Lunatic Asylum. - Dr. Oscar Woods, in his report for 1880 , again remarks on the objectionable practice prevalent in Ireland of committing lunatics to asylums as dangerous anc: criminal when they are neither the one nor the other. Because the ordinary mode of securing the admission of an insane patient to a public asylum provided by litw is tedious and involves trouble, the officials taking advantage of the special clause intended to meet exceptional cases, secure his speedy and convenient committal as a criminal. In the year 1879, I 277 patients were committed to Irish asylums as criminals, of whom probably not 2 per cent. had in any way broken the law, unless indeed insanity be itself regarded as a crime. The evils of such a system are sufficiently obvious. It brands as gaolbirds those who are merely the victims of disease; it produces agitation and alarm by entailing the interference of the police with those who regard them with repugnance and fear, and who are already probably nervous and apprehensive; and it deprives the medical officers of the asylum of that information which is so essential to successful treatment, for the police who convey the patients to the asylum as a rule know nothing of their previous history, and are at no pains to inquire. Surely in Ireland nothing should be done to obscure in the popular mind the distinction between crime and affliction, and yet this must be the effect of the method of dealing with lunatics that is now tolerated. Stringent orders should be at once issued securing a more faithful observance of the spirit of the Irish Lunacy Law.
NOTE ON THE APPLICATION OF THE ANTISEPTIC METHOD OF DRESSING TO CRANIO. CEREBRAL SURGERY.*

By GERALD F. YEO, M.D., F.R.C.S., Professor of Physiology in King's College, London.

THE object of this note is to give the results of experiments on the applicability of the antiseptic method of dressing to the brain and meninges, which were undertaken under the auspices of the Scientific Grants Committee of this Association.

The dangers which accompany operative procedure on the skull of man are too well known to require comment ; and, in the lower animals, operations involving the meninges generally set up inflammation, which it is almost impossible to check.

The use of the trephine has been gradually falling into discredit since the beginning of this century, because the admission of air into the cranial cavity proved to be nearly as fatal as the irritation which the operation sought to remove.

As our knowledge of the important part played by septic agencies in exciting inflammation increases, and our power of excluding them from wounds becomes more perfect, there is every reason to hope that operations on the cranium may be stripped of their terror, and its serous cavity opened with impunity. The greater insight given to intracranial affections, by the localisation of cerebral functions, seems to suggest that surgical aid may be sought in many cases which have hitherto been looked upon as quite beyond its reach. Thus, M. Broca was able to localise the situation of an abscess in the brain, and give exit to the pus; and M. Lucas-Championnère, in an able work, shows how cerebral localisation may greatly help cranial surgery.

In performing these experiments, I had the great advantage of the advice and assistance of Dr. Ferrier, whose knowledge of the function of the cortical centres is so well known.

Assuming - what all who have experience in the matter must admitthat Lister's method, when accurately carried out, excludes the septic vicissitudes to which wounds are liable, the following questions remain to be determined.

First : Is the inflammation, which very constantly follows exposure of the cranial contents, causer by septic agencies? and is it prevented by their exclusion? Or, can we assign other causes for this inflammation, such as the so-called general infection?

Secondly: What is the effect of strong carbolic solution ( $I$ in 20) on the meninges?

The uncomplicated cases, where antiseptic dressings were applied in man, are very few; and, in traumatic cases, so many complications exist, that it appears difficult to answer these questions from the experience gained from the human subject. Hence it appeared advisable to investigate the matter in the lower animals, where one might, at the same time, search for physiological truth. For this purpose, monkey's. were chosen-being the animals which, in septic receptivity, as well as their behaviour under chloroform and operation, most resemble man. A; far as possible, the animals were treated in the same way as human subjects.

The great difficulty of fixing the dressing was overcome by painting. the outside layers of the gauze with flexible collodion. Finding nothing to lay hold of on the smocth surface, the animals soon became used to their cap, and, after the first day, hardly meddled with it.

Before the operation, the scalp was purified with strong ( $\mathrm{I}$ in 5 ) solution of absolute phenol in oil or glycerine. The spray was used in afl but four cases, where it was omitted to see if it could be safely dispenced with, because it was difficult to prevent it cooling the animal. The edges of the wound were accurately brought together with sutureshorse-hair being found the best. It was found that the discharge was. so slight that drainage was unnecessary, and in the later cases it was omitted. Protective, which was not used at first, was found absolutely necessary to prevent irritation of the edges of the wound: Several layers of loose gauze, damped in a solution of $I$ in 40 , were placed over the wound, and these were held in position by about twenty turns of a narrow gauze roller, and the entire enclosed in three or four caps of gauze painted with collodion. The traphine was used in all cases for opening the skull, and a small bone-forceps was then applied to shape the aperture to the required size.

In drawing conclusions as to the efficacy of any one method of treatment, its results should be compared with those of other methods. Unfortunately, no statistical comparison can be made in the present research, as there are no records of the clinical history of any complete set of experiments performed without antiseptic precautions. This

* Towards the expenses of this research, a grant was made by the British Medical Association, on the recommendation of the Scientific Grants Committee. 